\title{
A LOCALIZED OUTBREAK OF TINEA CAPITIS (M. AUDOUINI) IN NORTHERN IRELAND
}

\author{
BY
}

J. MARTIN BEARE and E. A. CHEESEMAN

From the Royal Belfast Hospital for Sick Children and the Department of Social and Preventive Medicine, the Queen's University of Belfast

(Received for Publication July 7, 1950)

During the period June, 1948, to August, 1949, an extensive epidemic of tinea capitis occurred in Newtownards, a municipal borough of some 12,000 inhabitants, situated at the head of Strangford Lough in County Down and approximately eight miles east of Belfast. The town is essentially a market town serving the agricultural area of the Ards peninsula and as such is connected by good transport services to Belfast and the surrounding countryside. Subsequently it appeared that a single type, the normal or eugonic form of Microsporon audouini, was responsible for the outbreak in which as many as 368 children out of a population of some 3,000 under the age of 17 years were infected. Certain features of the epidemic appeared worthy of detailed study and the present paper sets out the aspects of clinical and statistical interest.

Studies of this type are usually handicapped by the absence of any information about the population from which the affected individuals are drawn. In the Newtownards epidemic, however, the infection was strictly localized to the town-all infected children were residents of Newtownards - and in fact 304 of the 368 infected children were attending one or other of five schools. Of the remaining 64 children, between 30 and $\mathbf{4 0}$ had not yet begun to go to school and the remainder went elsewhere. Through the courtesy of the Medical Officer of Health for County Down the five school populations, classified by age and sex, during the epidemic period, were made known to us. It has, therefore, been possible to make reasonably reliable comparisons of the incidence of infection between schools, age groups, and sexes by means of attack rates based on the average populations exposed to risk (Table 1).

Furthermore, it seems unlikely that many, if indeed any, of the infected children escaped examination, and it is reasonably certain that all the infected children attending school were detected. These facts, the abrupt onset of the outbreak and the finding that only one type of organism was incriminated, make the case histories collected particularly suitable for scientific analysis.

TABLE 1

Estimated Average School Populations during Period of Outbreak by Age and Sex

\begin{tabular}{|c|c|c|c|c|c|c|}
\hline \multirow{2}{*}{$\begin{array}{l}\text { Age in } \\
\text { years }\end{array}$} & \multicolumn{6}{|c|}{ School } \\
\hline & $\mathbf{A}$ & B & C & D & $\mathbf{E}$ & Total \\
\hline $\begin{array}{r}\text { Boys: } \\
4- \\
6- \\
8- \\
10- \\
12+\end{array}$ & $\begin{array}{r}37 \\
50 \\
40 \\
9 \\
-\end{array}$ & $\begin{array}{l}24 \\
33 \\
23 \\
26 \\
20\end{array}$ & $\begin{array}{l}35 \\
58 \\
51 \\
48 \\
55\end{array}$ & $\begin{array}{l}26 \\
54 \\
46 \\
69 \\
87\end{array}$ & $\begin{array}{l}14 \\
27 \\
17 \\
20 \\
16\end{array}$ & $\begin{array}{l}136 \\
222 \\
177 \\
172 \\
178\end{array}$ \\
\hline Total & 136 & 126 & 247 & 282 & 94 & 885 \\
\hline 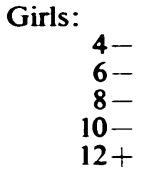 & $\begin{array}{r}36 \\
44 \\
36 \\
9 \\
-\end{array}$ & $\begin{array}{l}24 \\
25 \\
39 \\
26 \\
18\end{array}$ & $\begin{array}{l}42 \\
50 \\
47 \\
41 \\
50\end{array}$ & $\begin{array}{l}24 \\
42 \\
63 \\
70 \\
73\end{array}$ & $\begin{array}{l}18 \\
22 \\
25 \\
21 \\
24\end{array}$ & $\begin{array}{l}144 \\
183 \\
210 \\
167 \\
165\end{array}$ \\
\hline Total & 125 & 132 & 230 & 272 & 110 & 869 \\
\hline
\end{tabular}

Course and Control of the Epidemic

In retrospect it is known that the first case of tinea capitis in the outbreak occurred when a boy of 16 was infected. This boy had recently attended school, but had left when the infection was detected. Tinea capitis, due to $M$. audouini, has been endemic in Belfast for the past 20 years, and although no contact with a known Belfast patient was discovered, the most likely source of infection would seem to be an undetected Belfast case. In passing it is of interest to note that when, in 1941, a large number of Belfast children were evacuated to the Newtownards area, no cases of tinea capitis were subsequently reported in that area. 
All children were seen in the first instance at a makeshift 'ringworm clinic' set up at first in the local welfare clinic and later in an old decontamination hut in the town. Subsequently examinations were carried out in the schools by nurses using portable Wood's lamps and all schools were visited five times. Mass $x$-ray epilation was initiated in April, 1949, at the Royal Belfast Hospital for Sick Children, the infected children being transported to the hospital from Newtownards in groups of four or five twice daily. The details of the administration were materially the same as those advocated by Lewis, Silvers, Cipollaro, Muskatblit, and Mitchell (1944).

In order to obtain some indication of the rate at which the infection spread through the town, an estimate was made, for each patient, of the probable date of onset. Although in some cases this could be little more than an intelligent guess and in all cases could be only approximate, the estimated monthly distribution of fresh infections (Table 2 and Fig. 1) gives a definite pattern. After the initial cases of June, 1948, a steady increase in the monthly number of new infections was observed until after the summer school vacation and from October, 1948, until April, 1949, with the exception of February, the diagram assumes a plateau-like appearanceapproximately the same number of fresh infections occurring each month. In the exceptional month of February, 1949, it is estimated that there were 65 new patients, and this figure when compared with the lower level of 39 and 37 new infections in the months immediately before and after, can be explained by the introduction at the end of February of routine Wood's lamp examinations in the schools. After drastic measures to control the spread of infection had been taken and mass $x$-ray epilation begun, the number of fresh cases estimated for each month rapidly decreased and the last known patient was infected in August, 1949. Thereafter no new cases were discovered, alhough routine school examinations with Wood's lamps continued until October, 1949.

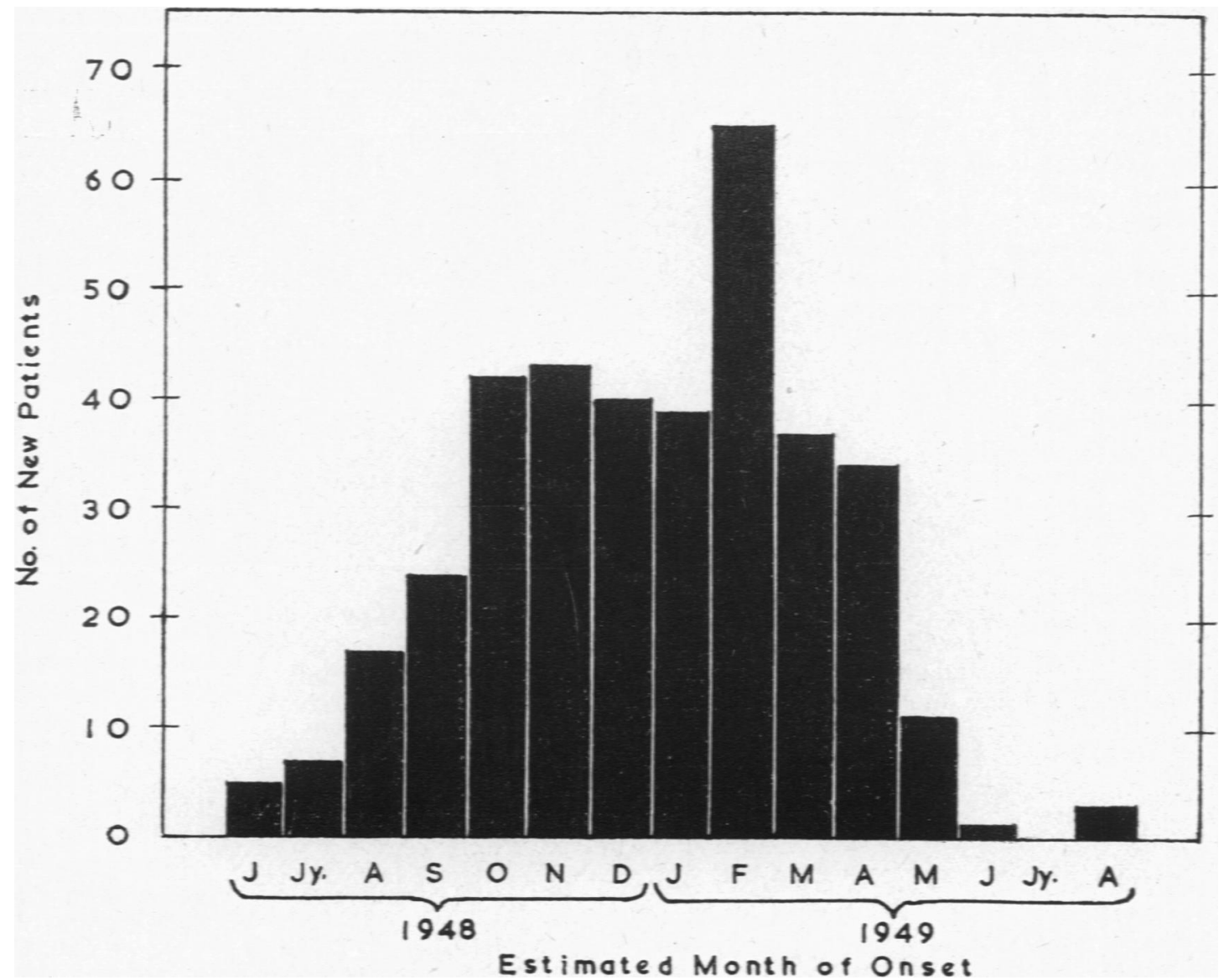

FiG. 1.-Distribution of patients by estimated month of onset. 
TABLE 2

Estimated MONTH Of ONSET

\begin{tabular}{|c|c|c|c|}
\hline \multicolumn{3}{|c|}{ Month } & $\frac{\text { No. of Patients }}{5}$ \\
\hline 1948: & $\begin{array}{l}\text { June } \\
\text { July } \\
\text { August } \\
\text { September } \\
\text { October } \\
\text { November } \\
\text { December }\end{array}$ & $\begin{array}{l}\cdots \\
\cdots \\
\cdots \\
\cdots\end{array}$ & $\begin{array}{r}5 \\
7 \\
17 \\
24 \\
42 \\
43 \\
40\end{array}$ \\
\hline 1949: & $\begin{array}{l}\text { January } \\
\text { February } \\
\text { March } \\
\text { April } \\
\text { May } \\
\text { June } \\
\text { July } \\
\text { August }\end{array}$ & $\begin{array}{l}\ldots \\
\cdots \\
\cdots \\
\ldots \\
\ldots \\
\ldots \\
\ldots\end{array}$ & $\begin{array}{r}39 \\
65 \\
37 \\
34 \\
11 \\
1 \\
- \\
3\end{array}$ \\
\hline \multicolumn{2}{|c|}{ Total } & & 368 \\
\hline
\end{tabular}

The Responsible Organism

Owing to administrative difficulties no routine cultures were made until the introduction of mass x-ray epilation in April, 1949. Thereafter specimens were taken as a routine procedure at the time of treatment and were cultured at the Department of Medical Mycology of the London School of Hygiene and Tropical Medicine (Walker, 1950). This cooperation was of inestimable value, since by knowing the organism responsible we have been able to draw definite conclusions regarding the mycology of the epidemic.
Of the 368 infected children, 278 were submitted to $x$-ray epilation and from all but 12 of these specimens of hair were obtained from which cultures were made. In 252 of the 266 cultures $M$. audouini was grown; in the remaining 14 no pathogen was isolated. A further 14 cultures were made from hairs of non-epilated children and in each case a positive $M$. audouini result was obtained. Although it might be argued that Microsporon canis, which is well known to eradicate itself spontaneously within a short time (Lewis, 1935), might have been cultured from some of the $\mathbf{8 8}$ children from whom specimens were not obtained, this seems to be unlikely for the following reasons. (1) Every positive culture obtained ( 252 out of 266 made from epilated children and all 14 made from non-epilated children) resulted in the isolation of $\boldsymbol{M}$. audouini. No other fungus was grown. (2) No small spore ringworm was known in the area before June, 1948, although a skin clinic has been functioning in the local hospital for many years. (3) The selection of cases for culture was, apart from 14 instances, entirely dependent upon attendance for $\mathrm{x}$-ray epilation, and while this did not result in a random sample of the entire 368 cases, it did result in every case which was seen after April, 1949, contributing a specimen for culture, except for those few patients who were not epilated because they were obviously clearing spontaneously. (4) In the non-epilated group of 90 children, 25 were members of families in which infected siblings had provided specimens from which positive $M$. audouini cultures had been made. (5) If $M$. canis infections did occur in the

TABLE 3

Average Incidence Rates by School Age and SeX

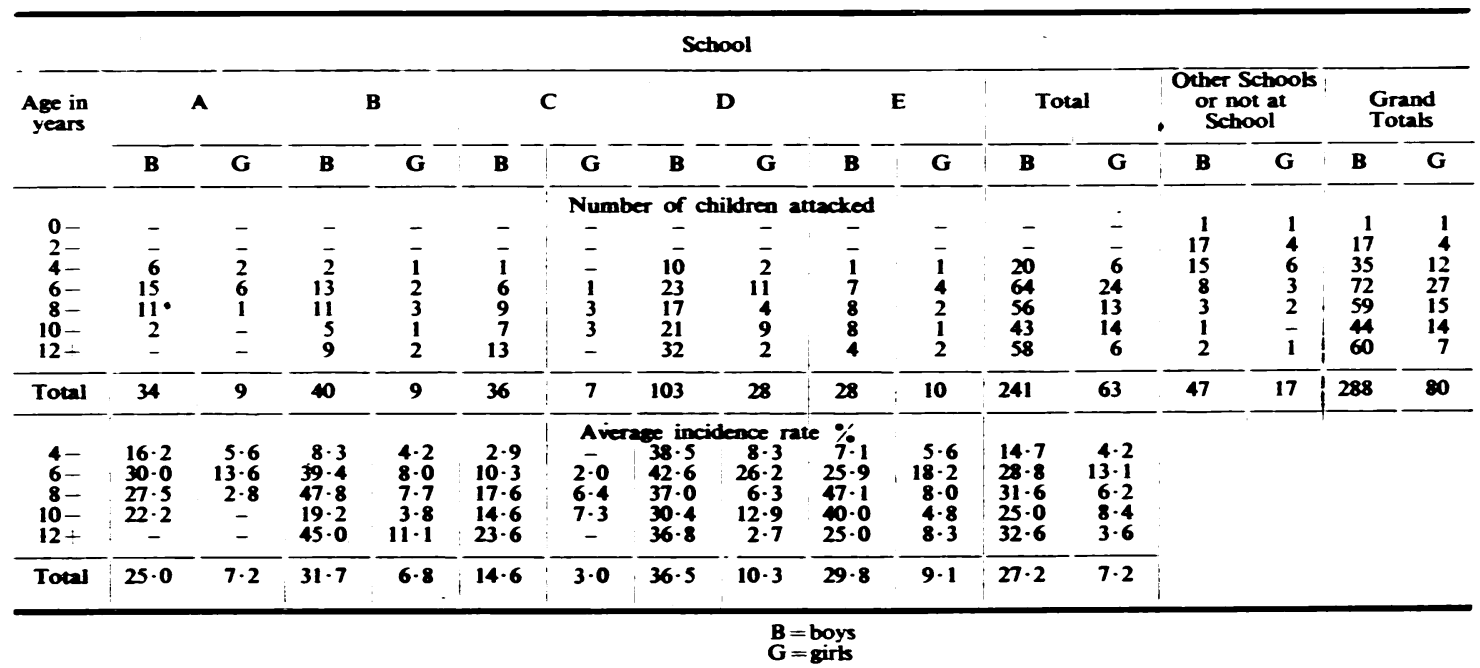


epidemic area, then they did so before the introduction of mass $x$-ray epilation and among persons who were spontaneously cured during the preepilation period. It seems most unlikely that this could have occurred, particularly when it is remembered that the 14 non-epilated children from whom specimens were obtained were all infected with $M$. audouini. Furthermore, since every case of tinea capitis seen gave typically green fluorescence under the Wood's light we feel that we can

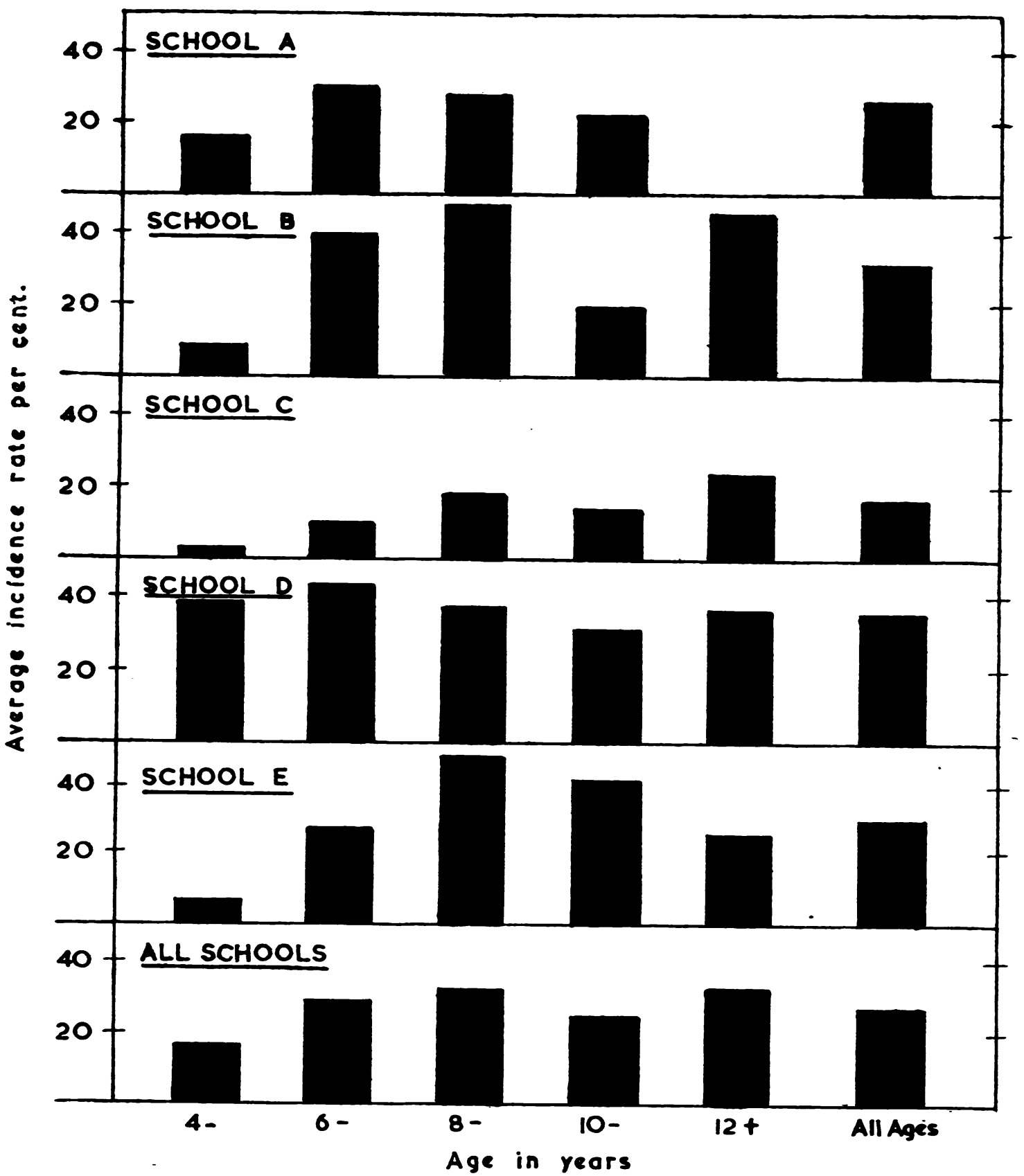

Fig. 2.-Average incidence for boys by age and school. 
incriminate $M$. audouini as the sole cause of the epidemic.

\section{Age and Sex Incidence}

Table 3 shows the distribution of the 368 infected children according to their age, sex, and school attended. (For the purposes of this paper we have identified the schools by the letters A, B, C, D, and $E$.) For the five schools incidence rates based on the average populations (see Table 1) have been calculated for each sex and age group and these rates also appear in Table 3. For the purposes of the following comments on age and sex incidence of the infection the argument is limited to those children attending the five schools.

A study of the table reveals the striking difference in the level of attack between the sexes. In each school and at each age group the attack rate amongst boys was consistently greater than that amongst girls. The consistency of this finding conclusively demonstrates the greater liability to infection of boys than girls, a fact which has been commented upon elsewhere (Keddie, 1947 ; Schwartz, Peck, Botvinick, Leibovitz, and Frasier, 1946; Miller, Lowenfish, and Beattie, 1946; Barlow, Chattaway, and Whewell, 1950).

No consistent age trend in the rates was apparent even if our attention is confined to the experience among boys for which the numbers are sufficient to give a reasonable picture. In Fig. 2 the rates at different age groups in each boys' school have been shown diagrammatically. Generally, it appears from this diagram, that the peak ages of attack occurred after the age of 6 and, in all but one school, under the age of 10 years. For all boys' schools combined, the age group of maximum infection is by no means clearly defined and apart from the first age group, 4-5 years, when the rate was about $15 \%$, in all other age groups there was very little variation, the range being approximately $25-33 \%$.
We have not been able to trace any other published data in which the infected population has been examined in relation to the population from which it is drawn. Thus, we cannot compare our age incidences with those obtained elsewhere. In Keddie's (1947) series of 312 boys, about $11 \%$ were under $5,49 \%$ between the ages of 5 and 11 , and $40 \%$ between the ages of 12 and 14 . In our series just over $20 \%$ of the infected boys were above the age of 12 , but the comparison is really meaningless without reference to the parent populations.

\section{Comparison between Schooks}

It is clear from the crude rates that quite material differences existed in the incidence of infection in different schools. How much of that variation is due to the fact that the infection was spreading in small communities of different age and sex composition is, however, not apparent from the crude data of Table 3. We can summarize the experience and at the same time eliminate the effects of populations whose ages are differently constituted on the comparison in the following way. If there were no differences in the incidence in different schools each school would have the same age and sex specific incidence rates as have been found for all schools combined. If then, for any one school we multiply the age specific rates for all schools combined by the population in the appropriate age group in that school, we shall obtain at each age group the number of infections which we should expect to find if there was no difference between the schools. The ratio of the total number of infections in any one school to the number so expected gives us a relative measure of the departure of observation from expectation based on a hypothesis of no ' between school ' differences. We have made such calculations, for each sex separately, with the following results:

\begin{tabular}{|c|c|c|c|c|c|c|}
\hline & & Boys & & & Girls & \\
\hline School & $\begin{array}{l}\text { Observed } \\
\text { Infections }\end{array}$ & $\begin{array}{l}\text { Expected } \\
\text { Infections }\end{array}$ & $\begin{array}{r}\text { Observed/' } \\
\text { - Expected (\%) }\end{array}$ & $\begin{array}{l}\text { Observed } \\
\text { Infections }\end{array}$ & $\begin{array}{l}\text { Expected } \\
\text { Infections }\end{array}$ & $\begin{array}{r}\text { Observed } \\
\text { Expected }(\%)\end{array}$ \\
\hline $\begin{array}{l}\mathbf{A} \\
\mathbf{B} \\
\mathbf{C} \\
\mathbf{D} \\
\mathbf{E}\end{array}$ & $\begin{array}{r}34 \\
40 \\
36 \\
103 \\
28\end{array}$ & $\begin{array}{l}34 \cdot 8 \\
33 \cdot 3 \\
67 \cdot 9 \\
79 \cdot 5 \\
25 \cdot 4\end{array}$ & $\begin{array}{r}98 \\
120 \\
53 \\
130 \\
110\end{array}$ & $\begin{array}{r}9 \\
9 \\
7 \\
28 \\
10\end{array}$ & $\begin{array}{r}10 \cdot 3 \\
9.5 \\
16.5 \\
18.9 \\
7.8\end{array}$ & $\begin{array}{r}88 \\
95 \\
43 \\
148 \\
128\end{array}$ \\
\hline
\end{tabular}


Thus, apart from differences due to differently constituted age distributions of the population it appears that the risk of infection both among boys and among girls was greatest in school D, where observation exceeded expectation relatively more than in any other school. At the other end of the scale the risk of infection appeared to be least among both boy and girl pupils at school C; for each sex this school had the lowest ratio of observed to expected infections. Moreover, there is fairly good agreement between the two sexes when the schools are arranged in numerical order of their ratios. For boys the order, from highest to lowest, is D, B, E, A and C; while for girls the order is the same except that schools $B$ and $E$ are interchanged.

School D is the most recently built school of the five, and is a modern and well-equipped building; on the other hand the housing in the part of the town served by that school is unfortunately of a low standard. School A receives children only up to the age of 11 after which they are transferred to school $\mathrm{D}$; thus, while both schools usually have on their rolls members of common families, school A for the most part was known to have as pupils children of young parents. These parents are locally known for their enthusiastic cooperation in school health programmes; for example, the School Medical Officer has noted the more frequent attendance of parents at routine examinations at school A than at others. School C is considered locally as the best school in the town. Both boys and girls attend each school, and as a general rule the wearing of hats or caps is not compulsory. Thus, it is not surprising that the lowest incidence of infection was reported from school $\mathrm{C}$, and the high incidence at school D also seems compatible with local impressions.

\section{Clinical Description}

From experience gained in Newtownards the clinical appearance of tinea capitis due to $\boldsymbol{M}$. audouini has become clear. The reaction on the part of the host has been seen to vary from a kerion quite as severe as that which can be caused, for example, by Trichophyton discoides, to absolutely no reaction whatsoever. A few patients have been seen where the infection, in the absence of local treatment, has resulted in considerable and probably permanent scarring; others have been seen where, in spite of the most careful clinical examination, it has been impossible to localize the site of infection. In cases such as the latter, however, when examined by means of Wood's light, large areas of the scalp fluoresced brilliant green and subsequently cultures proved to be positive. These two extremes of host-parasite relationship of gross antagonism and perfect equilibrium are not frequently observed; for example, in the 368 patients of the present series only six showed severe kerion reaction.

All the intervening grades of inflammatory reaction were seen, but the most common reaction was that usually described as 'grey baldness". From the diagnostic point of view the most troublesome cases are those which clinically present either no abnormality or only slight dandruff. Patients so affected act as carriers of infection for long periods, since the general practitioner, without the advantage of Wood's light examination, is unlikely to detect such infected children, and indeed parents may be unaware that their child is infected.

If patients with tinea capitis are observed over a period of months without treatment it can be seen that the tendency is eventually towards the development of host-parasite equilibrium: in other words, the inflammatory reaction is most severe at the beginning of the infection. At that stage the intrafollicular part of the hair alone may be fluorescent (seen after manual epilation), and during the initial weeks the hair shafts remain intact. If the fluorescent part extrudes from the hair follicle the tendency for the hairs to be broken becomes apparent, and it is then that partial baldness is seen clinically in those cases where it occurs. Later the hair tends to get longer though still infected, and in very long-standing cases, such baldness is not a clinical feature and the entire length of hair, even up to two inches, may show green fluorescence under Wood's light. Clinically in cases at this stage the usual detectable abnormality is dandruff but there may be no clinical abnormality at all. In fact, old cases of $M$. audouini infections have often been seen in which a quarter to a half of the entire scalp was fluorescent and yet there was no baldness.

The importance of dandruff as a clinical sign of infection is borne out by the case report of three members of a family - two boys aged 10 and 2 years and one girl aged 8 years-seen during the same period in Belfast. All were diagnosed as suffering from tinea capitis by their private doctor, and after treatment with iodine and Whitfield's ointment all three were declared clear and the two eldest children returned to school. Nine months later these two children came up for routine Wood's light examination at their school and were found to be positive. The whole family was referred to the clinic. The oldest child appeared, on clinical inspection, to be perfectly normal, but under Wood's light the entire scalp showed scattered small tufts of fluorescent hairs, some of which were a half-inch to an inch in length. The girl, clinically, revealed extensive dandruff over the top of the scalp but no sign of any alopecia. Without the aid of Wood's light a 
diagnosis of mild seborrhoeic dermatitis would certainly have been acceptable. Under Wood's light, however, the appearance was astonishing; almost the entire top of the scalp was fluorescent. Hairs of an inch or more in length were fluorescent right to their extremities. The youngest child of the family also had slight dandruff but again under Wood's light the entire top of the head was fluorescent.

Site of Infection. Although in all case histories the infected parts of the scalp were charted, we do not present a detailed analysis of these records since each refers to different stages of the disease. Unfortunately it was not possible to record the original sites of infection, as was done by Kinnear and Rogers (1948), who found that $56 \%$ of their series of boys and $32^{\circ}$ of their girls were initially infected on the occipital region, and that $65 \%$ of the boys had the infection on the so-called clipper area. For what it is worth our records show that $82^{\circ}$ of 214 boys and $64^{\circ}$ of 56 girls, analysed from this point of view, had some infection on the occipital region at the time of examination.

Wood s Light. In the early infections fluorescence under Wood's light is of the most brilliant green, and as the infection becomes older so the brilliance diminishes until in very long-standing cases the fluorescence is of a dull blue colour. The number of infected hairs in any one area diminishes with the age of infection while the length of infected hairs increases. These factors greatly facilitate the estimation of the duration of an infection in any particular patient, and it has been our experience that estimates of duration of infection made in this way, when a child was seen a second time but before reference had been made to his or her original case rote, were frequently remarkably accurate. The cycle mentioned above is, in our experience, comparable with that which occurs in $M$. canis infections, except that in the latter it is much more rapid: in general it appears that a $M$. canis infection of some two to three months duration resembles under Wood's light a $\mathbf{M}$. audouini infection of about a year's duration. However, there is nothing mathematically fixed about this, and by observing $M$. audouini infected children at repeated intervals the process appears to occur at slightly different speeds, and our impression is that where the cycle is occurring relatively quickly spontaneous cure is to be expected. So it was that in Newtownards during the three to four week period when most of the $x$-ray epilations were carried out, and when a waiting list was desirable, we were able to leave many cases which we thought were undergoing spontaneous cure to the end of the list; in fact, we did find that many were cured spontaneously before their turn for epilation was reached.

\section{Spontaneous Cures}

Of the total 368 infected children, 90 were not submitted to $x$-ray epilation and of these all but three can be regarded, from the point of view of this analysis, as spontaneous cures. The details regarding these three children are as follows:

Case 1. This is a boy whose parents consistently refused to permit epilation and who, at the time of writing, is still extensively affected with tinea capitis.

Case 2. A girl, aged 9 years, was treated for one month with salicylanilide in pentaglycol by lccal applications and then was clear. In this case it is possible that the cure might be attributed to the preparation used.*

Case 3. A boy of 3 years was treated for four months in the same way as Case 2 but without any apparent effect. The condition was finally eradicated by manual epilation.*

The remaining 87 cases had no specified treatment because routine manual epilation was not carried out in the early stages owing to the pressure of examinations at the clinic. We do know, however, that in several cases various home remedies were applied -boot polish, butter and treacle, washing soda, and so on. Their use was actively discouraged and on no occasion was a reaction of contact dermatitis type seen. In several cases patients were treated by their family doctors with such preparations as Whitfield's ointment locally and testosterone internally. Our impression is that such treatments did little or nothing towards effecting a cure, but again this is, and can only be, an impression.

Various incidence rates of spontaneous cure appear in the literature. Thus, Lewis, Hopper, and Reiss (1946) state that

\begin{abstract}
- The tendency of approximately $10^{\circ}{ }_{\circ}$ of the patients to spontaneous recovery and consequent success with the use of local remedies alone is reflected in the 32 patients who were so cured in an average time of six to eight weeks."
\end{abstract}

Livingood and Pillsbury (1941) who followed up 125 cases of $M$. audouini tinea capicis, mainly in coloured children, found $20(16 \%)$ with evidence of inflammation before or following local treatment and 14 of these became cured without $x$-ray epilation. And of 105 cases of non-inflammatory $M$. audouini infection of the scalp $28(27 \%)$ cured spontaneously in periods varying from three months to two years. Shaffer in a discussion of a paper by Wilson (1949) directs attention to a random sample

- These were the only two Newtownards patients treated with salicylanilide preparations. It is proposed to report our experience with such preparations in the treatment of Belfast patients at a later with suce. 
drawn from 7,000 untreated cases in Detroit, in which $70 \%$ were spontaneously cured within three years. Shaffer comments upon the absence of any difference in the rate of cure for young children and those nearing puberty. Epstein (1938) demonstrated attenuation of the dermatophyte Trichophyton gypseum by repeated passages from animal to animal. Subsequent inoculations produced abortive lesions or even failed to infect the animal. Though $M$. audouini is not a parasite of lower animals yet this same explanation may account for the high incidence of spontaneous cures observed by us, and, over a longer period, by Shaffer, since we were both dealing with $M$. audouini in epidemic form.

Unfortunately the present series of 87 'spontaneous cures' cannot be legitimately considered as a representative sample of all the spontaneous cures which might have occurred in the Newtownards epidemic if mass $x$-ray epilation had not been introduced. Several of the epilated children appeared to contract the infection early in the epidemic, and any attempt to estimate the average duration of infection among spontaneously cured children is bound to be an understatement. Since the period of infection in any single case can only be obtained from the estimated date of onset and the date when first negative to Wood's light, we feel that the data would be too approximate to attempt any refined statistical technique aimed at calculating the probability of spontaneous cure in specified periods. At the most, therefore, it seems that if we are prepared to ignore home treatments and the like, the data suggest that within the maximum period of 15 months the incidence of spontaneous cure must be somewhat higher than the proportion of spontaneous cures observed by us, namely, 87 out of 368 , i.e., $24 \%$. It is of interest to note that we observed a patient, a boy of 16 years, whose infection was almost certainly cleared by the development of puberty. However, it is unlikely that such an explanation could be true of many of the spontaneous cures, since of the total 87 as many as 61 were below the age of 12 years.

Livingood and Pillsbury (1941) noted that the chance of spontaneous cure was greatly increased if inflammation occurred, but even in cases in which no inflammation occurred many $M$. audouini infections did become spontaneously cured. These authors observed concomitant non-inflammatory $M$. audouini infections of the scalp in five sets of brothers in which infection of one brother in each pair became cured after persistent local treatment, while that of the other did not. We, too, have frequently seen spontaneous cures among some members of a family when epilation has been necessary for others. One assumes that the organism in such families is the same and that there are no different strains in such cases. In this context the observation of tinea capitis in like twins, though not of this series, is of particular interest.

Both girls were seen in Belfast on February 21, 1949, for the first time; at that date they were aged $4 \frac{1}{2}$ years. Both were extensively affected with non-inflammatory, brilliantly fluorescent tinea capitis. The mother's story indicated that the onset of infection had occurred some three months earlier. When cultures were made from hair specimens no pathogen was isolated in the case of one twin, A, and a positive M. audouini was obtained from the other, B. X-ray epilation was ordered for $B$ and salicylanilide in carbowax for $A$; but both children defaulted. The mother was repeatedly written to and asked to attend the clinic, and the family were eventually seen again on November 9 , 1949, some nine months after their first visit. The mother stated that she had applied the ointment to A's head repeatedly but she had done nothing for B. On examination under Wood's light it was found that $B$, from whose hair the original positive culture had been made, was free from infection; on the other hand, A, who had the original negative culture, was still infected. The opportunity was taken to have a new culture grown from the hair of $A$ and on this occasion a positive $M$. audouini growth resulted. She was eventually successfully treated by $x$-ray epilation.

Here, then, is a very striking example of two children so alike in appearance that an outsider could not have distinguished one from the other, one of whom cleared without any treatment whatsoever while the other remained grossly infected after a period of at least nine and probably 12 months. It was noted when the twins attended the clinic on the second visit that each was wearing exactly the same kind of clothing and the mother was seen to replace their hats after our examination without any apparent thought. On direct questioning she admitted that she never made any attempt at any time to distinguish the clothing of the two children. Thus, hats, combs, pillowcases, hair clips, etc., were used without regard to the fact that one child was infected while the other was not. So for a period of some months the child we have called B was repeatedly exposed to infection and her spontaneous cure had apparently been followed by a very considerable immunity.

Again, like Barlow, Chattaway, and Whewell (1950) we would stress that to the clinician the most important sign of tinea capitis in a child is dandruff and not alopecia and that consequently Wood's light is absolutely essential for the diagnosis of the condition. The case report of the family of three 
children mentioned earlier is a striking example of the value of Wood's light. For our part, we do not agree with those who would rely entirely upon the microscopical examination of suspicious hair stumps since we have frequently seen cases where clinically no such hair stumps were visible.

\section{Reinfections}

Only one case in our series could be considered as a reinfection. In the first instance the boy concerned was successfully epilated by x-ray; he was examined and found free of infection. He went back to school, but was detected a month later with two patches of circinate erythema and within these patches numerous fluorescent stumps were found. These patches were not on the sites originally affected and the second infection was cleared by extensive manual epilation.

\section{Summary}

An outbreak of tinea capitis in Newtownards, County Down, between June, 1948, and August, 1949 , is described. During those 15 months, 368 children under the age of 17 were affected, an incidence rate in the population at the same ages of about $12 \%$.

The age and sex incidence rates have been calculated for the pupils of five schools, which accounted for 304 of the patients. Boys were consistently more liable to infection than girls; $27.2 \%$ of the male school population was infected compared with $7 \cdot 2 \%$ of the corresponding female population. There was no apparent association between age and incidence of infection.
The different levels of incidence of infection experienced by the five different school communities suggest that the epidemic was more severe in some parts of the town than in others.

The organism responsible for the outbreak was $M$. audouini, and no other fungus was grown from 280 cultures made during the course of the outbreak.

A clinical description of the infection has been given and the value of Wood's light in the detection of infected children is emphasized.

We are indebted to Mrs. J. Walker of the Department of Medical Mycology in the London School of Hygiene and Tropical Medicine for carrying out the culture work. Other information and help was given by Professor F. M. B. Allen, Drs. Ivan H. McCaw, Reginald Hall, Douglas Boyd, J. B. McKinney and John Scott, and by Mr. J. D. Merrett.

\section{References}

Barlow, A. J. E., Chattaway, F. W., and Whewell, C S. (1950). Brit. J. Derm., Syph., 62, 251.

Epstein, S. (1938). J. invest. Derm., 1, 141.

Keddie, J. A. G. (1947). Hlth. Bull., Dept. of Health for Scotland, 5, 66.

Kinnear, J., and Rogers, J. (1948). Brit. med. J., $2,854$. Lewis, G. M. (1935). Amer. J. med. Sci., 189, 364.

-, Hopper, M. E., and Reiss, F. (1946). J. Amer. med. Ass., 132, 62.

—, Silvers, S. H., Cipollaro, A. C., Muskatblit, E., and Mitchell, H. H. (1944). N. Y. St. J. Med., 44, 1327.

Livingood, C. S., and Pillsbury, D. M. (1941). J. invest. Derm., 4, 43.

Miller, J. L., Lowenfish, F. P., and Beattie, G. F. (1946). J. Amer. med. Ass., 132, 67.

Schwartz, L., Peck, S. M., Botvinick, I., Leibovitz, A. L., and Frasier, E. S. (1946). Ibid., 132, 58.

Walker, J. (1950). Brit. J. Derm. Syph., 62, 239.

Wilson, J. F. (1949). Arch. Derm. Syph., 60, 347. 